\title{
SOCIO-PSYCHOLOGICAL IMPLICATIONS OF THE OUTBREAK OF COVID-19: ISSUES, CHALLENGES AND FUTURE PROSPECTS
}

\author{
MANZOOR AHMAD MALLA, HILAL AHMAD WAR ${ }^{l}$
}

\begin{abstract}
The outbreak of coronavirus (COVID-19) occurred in the capital of Hubei province in China in December 2019, and has since engulfed almost all sectors of society across the globe, irrespective of age, sex, race, religion, or color. Exposure to COVID-19 has increased the risk of numerous socio-psychological problems such as the risk of domestic violence, suicidal behavior, social stigma and discrimination, human-rights-related challenges and crime, depression, anxiety, stress, phobias, confusion, traumatic events, and other mental health problems. This article describes the socio-psychological implications pertaining to the spread of coronavirus, how it has caused numerous deaths, and how developing and developed countries alike have imposed lockdowns, curfews, and restrictions on public movement, affecting markets, workplaces, construction sites, and transport facilities, while members of society have been instructed to maintain social distance, adversely affecting their day-to-day lives. This study is based on a comprehensive review of literature, as well as data regarding the socio-psychological implications of COVID-19. The study concludes that the outbreak of COVID-19 has catastrophic socio-psychological implications, especially in developing countries, where the vulnerable in society are hit hard. The study suggests that there is a great need for the attention of policy makers and planners in relation to responding to the COVID-19 crisis.
\end{abstract}

KEYWORDS: COVID-19, social implication, psychological problems, stress, violence

\footnotetext{
1 Manzoor Ahmad Malla is a PhD candidate at the Department of Sociology, Maulana Azad National Urdu University, Hyderabad, India. Email: manzoorahmadmalla41@gmail.com. Hilal Ahmad War is $\mathrm{PhD}$ at the Department of Sociology, Maulana Azad National Urdu University, Hyderabad, India. Email: spcbio121@gmail.com.
} 


\section{INTRODUCTION}

The coronavirus plague emerged in Wuhan city in China in December 2019, and has since engulfed many developed and developing countries around the globe. It poses a major threat to humanity, and a serious challenge to health organizations, social scientists, and medical professionals. The director general of the WHO acknowledged that the outbreak of "Coronavirus as pandemic" is due to the dramatic increase in COVID-19 positive infections and deaths (Mahase, 2020). The ongoing reporting of experts, national and international organizations, and media coverage and research indicates that coronavirus disease is increasing at an alarming speed on a global level, and that the large number of deaths and infections will continue to rise if not controlled adequately. Congestion and crowding, especially in slum and refugee areas, may exacerbate the human tragedy and humanitarian crisis, and will have disastrous consequences due to poor sanitation and lack of hygienic drinking water and other facilities (Lacobucci, 2020). The situation in care homes, and the lack of personal protective equipment increases the risk of viral infections (Lacobucci, 2020). Countries across the globe imposed health emergencies due to public health risk through the international spread of disease (Zhou, 2020). Individuals with disabilities, migrant workers, and those with cardiovascular disease, respiratory problems, and physiological disorders are more prone to the effects of the pandemic (Armitage et al, 2020; Parkin, 2020; Singh et al, 2020; Chen et al, 2020). Mobile apps have been developed which could help with tracing patients with symptoms of coronavirus (Mayor, 2020). To tackle such emerging problems, the Secretary General of the United Nations, Antonio Guterres, has said that the least developing countries need fully fledged support and aid from the global community to control the plague. Knowing that coronavirus is harmful to humanity, the General Secretary of the UN has said that the coronavirus epidemic could increase the incidence of other diseases such as cholera and measles and is "threatening the whole of humanity, and the whole of humanity must fight back." He added, in announcing the related initiative, that "global action and solidarity are crucial. Individual country responses are not going to be enough" 2 . As on 31 january 2021, there were 102 139771 confirmed cases, 2211762 confirmed deaths, and 222 countries

\footnotetext{
2 Al-Jazeera (2020, March 26). UN launches virus aid plan, says all of humanity at risk. https:// www.aljazeera.com/news/2020/03/launches-virus-aid-plan-humanity-risk-200325170858275. html. Accessed April 6, 2020.
} 
and territories were affected by the virus globally.$^{3}$ Since it has taken a heavy toll across the globe, therefore to tackle COVID-19, the World Health Organization said that every country immediately needs protocols and firm action to mitigate the risks of the spread of COVID-19.

The outbreak of the COVID-19 crisis is likely to have long-lasting sociopsychological implications beyond the global health crisis, which may increase threat to the development, stability, and security of both developed and developing countries. An eminent Brazilian security expert has said that "Covid-19 represents the most significant threat to population especially to the health and political and economic stability in a generation" (Kim, 2020). As far as the social implications are concerned, the pandemic has created widespread social disorder, social chaos, social disorganization, and social problems, such as an increase in domestic violence cases, social insecurity, hunger, reverse migration in some regions, and violence against medical professionals, etc. The emergence of this contagious disease not only causes fatalities, but also poses a great threat to the social security, services, national capacity, and general development of society (World Bank, 2020). Marginalized and poor sections of society, such as migrant workers, street vendors, and daily wage laborers, have been at increased risk, including that of suicide, violence, and many other issues, as individuals are stuck at home. In this regard, a study entitled "Suicide Mortality and coronavirus disease 2019 - A perfect storm" led by Mark Reger reported that the incidence of suicide and family-related violence could increase in the current circumstances due to the ongoing loss of jobs, income sources, business earnings and trade, as well as the lack of social contact, community support, and social hardship (Reger et al, 2020). Further, Chiara Crespi in Northern Italy found that healthcare workers and people residing in Northern Italy have been adversely affected. Crespi reports that feelings of loneliness, wretchedness, and an increase in stress are the major impacts of the pandemic (Crespi et al, 2020). The crisis has created unique changes in social structures and public health, and is leading to social stigma, discrimination, suicidal behavior, the violation of human rights, and an increase in the risk of family violence and other criminal activity. The COVID-19 crisis has also weakened the social fabric of society and created a formerly unimaginable situation.

Additionally, the epidemic outbreak of COVID-19 has created psychological depression and mental health deterioration among many parts of society. A

3 COVID-19 Weekly Epidemiological Update Data as received by WHO from national authorities, as of 31 January 2021,https://www.who.int/docs/default-source/coronaviruse/situationreports/20210202_weekly_epi_update_25.pdf?sfvrsn=b38d435c_4\&download=true. Accessed February 5, 2021 
shortage of essential services such as food, shelter, clothes, and medicine has already caused psychological distress among the vulnerable. A lot of people have become victims of psychological disorders and traumatic events due to their social isolation, hopelessness, forced quarantine, unhappiness, the death of beloved ones, infection with the virus and loneliness. Studies have reported that the epidemic of COVID-19 will increase psychiatric disorders, particularly among those who are infected and dealing first-hand with the epidemic (Carvalho et al, 2020). A study conducted by Xin Bo and his colleagues found that more than 96 percent of COVID-19 infected patients experienced post-traumatic stress symptoms. The study further says that the outbreak of COVID-19 will lead to an increase in psychological disorders (Xin, 2020). Exposure to a diverse range of COVID-19-related distress and hardship has increased the risks of mental health problems among large segments of the affected population. A study entitled "Nationwide Survey of Psychological Distress among Chinese People in the COVID-19 Epidemic," led by Jianyin Qiu and his associates revealed that the outbreak of COVID-19 has seriously damaged the psychological and mental health of individuals. Further, the study also reported that it has caused a wide range of psychological disorders such as depression, anxiety, stress, and panic disorders (Qiu et al, 2020). There are number of negative implications of the COVID-19 pandemic, such as stigmatization, job loss, discrimination, feelings of loneliness, forced quarantine, a lack of social contact, a lack of social security and essential commodities, social isolation, etc. that have triggered mass psychological distress among those who are affected, who thus need immediate medical intervention. In fact, COVID-19 has had catastrophic implications for every sector of the affected societies, including the social, political, economic, and health sectors, and has created socio-economic problems, psychological issues, and physical and mental health deterioration. The present study explores the socio-psychological implications, issues and challenges related to COVID-19. There is a dire need for the study and better understanding of the COVID-19 pandemic and its impact on the masses from socio-psychological perspective.

\section{METHODOLOGY}

The study we describe here is theoretical in nature, and based on primary and secondary data such as the publications of state, local, and central governments, newspapers, media coverage, research articles, paper publications, magazines, the publications of national and international organizations, and reports of scholars, etc. Data were primarily collected from various government official 
reports, newspapers, journals, and from the records of national and international organizations, websites, and statistics. Additionally, data were also collected through telephone interviews, observations, and recordings. Therefore, the authors rely on multiple secondary sources to highlight a variety of sociopsychological problems caused by the outbreak of COVID-19 at the global level.

\section{THE SOCIAL IMPLICATIONS OF COVID-19}

The outbreak of COVID-19 has profound implications, not only for the health of human beings, but for many other areas of society, including family, religion, government, education, and economic institutions, as well as psychological health, security, and individual standards of living. The pandemic is likely to cause and accelerate multidimensional social issues, such as increasing the incidence of poverty, suicide, unemployment, family violence, hunger, social insecurity, criminality, mass displacement, reverse migration, violence against healthcare staff, human-rights related challenges, and domestic violence against women and children, as well as stigmatization and discrimination generally. Frontline workers such as doctors, nurses, paramedics, sanitation workers, burial teams, security forces, and those communities directly affected by the coronavirus are facing social stigma and discrimination. A document prepared by the United Nations International Children's Emergency Fund in March 2020 under the heading "Social stigma associated with the coronavirus disease (COVID-19)" reported that the pandemic-related crisis has triggered stigmatization, prejudice, and discriminatory behaviors against people, especially healthcare staff, law enforcement agencies, communities affected with the virus, caregivers, the kin of infected and deceased patients, friends, neighbors, people with a history of recent travel, and residential areas affected by the virus (UNICEF, 2020). Since the outbreak of coronavirus, many people and religious ethnic groups have been labeled and discriminated against due to their perceived association with the coronavirus disease. Nida Moukaddam and Asim Shah have noted that, "stigma and xenophobia are two aspects of the societal impact of a pandemic infectious outbreak" (Moukaddam et al, 2020). Many people do not have any direct link with the disease, but reside within communities in which they may suffer from discrimination and stigma, along with the residents. In many places in India, groups of people and communities have claimed that people in neighboring areas have boycotted interaction with them, as well as labeled them as carrying the virus. Such behavior may give birth to other social and mental health issues, like feelings of loneliness and helplessness. Such people may avoid going for 
health checkups because they prefer to escape social stigma and discriminatory behavior. The establishment of quarantine centers has had shocking implications for senior citizens, disabled persons, the poor, children, and people with chronic health conditions. Besides the need to maintain social distance, restrictions on social gatherings and continuous lockdowns can have long-lasting impacts on families and communities. Jeff Lagasse has maintained that social isolation, a lack of communication, feelings of loneliness, forced quarantine, and a lack of community support or involvement can heighten the impact of other healthrelated issues (Lagasse, 2020). Removing people from their day-to-day social, economic, religious, and cultural surroundings can result in chaotic situations and can also affect their well-being. Poor and weaker sectors of society such as daily wage workers, senior citizens, disabled people, migrant laborers, private employees, etc. have been severely affected. The situation of continuous lockdown has created manifold problems in society, especially for poor people who are unable to manage their food and shelter; but also for older people who may find themselves isolated from their families since breadwinners may be unable to return home, while migrants' and daily wage laborers' rations may run out.

The pandemic crisis has resulted in violations of human rights, especially attacks on healthcare staff, security personnel, forced quarantine, forced displacement, and reverse migration. The regional director of the WHO for Europe reported that the outbreak of COVID-19 poses a major threat to the many vulnerable groups in society, and is linked to increasing violence against women, children, frontline workers, and the public in general. ${ }^{4}$ For instance, in India, millions of migrant laborers, poor families, and people living in slums or congested and at-risk areas have been forced to quit work and return to their homes, in the absence of transport facilities. Thousands of people such as pujaris, clergymen, priests, imams, and religious heads have been sent to jail for violating laws and restrictions. A lot of people have been injured, beaten, and put behind bars due to violations of law and order. Many people around the globe, especially in India, such as street vendors, vegetable and fruit sellers, and sometimes health professionals as well as people who have left their homes for essential commodities, have been humiliated and punished by paramilitary and police forces, representing a challenge to their human rights. Moreover, misinformation and false news circulating in social media have also had devastating consequences. For example, in Iran 100 people lost their lives and thousands are on ventilators after drinking alcohol in the hope that this would save them from COVID-19, due to inappropriate guidance (Aitken,

$4 \mathrm{WHO} / 2019-\mathrm{Ncov} / \mathrm{SRH} /$ Rights/2020 
2020). The outbreak of coronavirus has also increased the risk of suicide. The French sociologist and founding father of Sociology, Emile Durkheim, claimed that people are more prone to the risk of suicide when they live under extreme social pressure, feel detached from the bonds of group life, and are cut off from the majority of society (Mukherjee - Ghosal, 2006). Similarly, during the lockdowns associated with COVID-19, many medical professionals, workers, laborers, businessmen and people of other backgrounds have committed suicide due to a fear of isolation, alienation, loss of their loved ones, and the rapid breakdown in the social structure. Since the outbreak of COVID-19, an increase in the incidence of suicide among healthcare staff and other frontline workers has also been identified (Dutheil et al, 2019). Epidemic-related issues such as forced quarantine, social isolation, discrimination, stigma, social distancing, and economic recession can increase the risk of suicide. Many pieces of research have observed that economic recessions (Oyesanya et al, 2015) and a lack of community and religious support may increase suicidal ideation (Tayler et al, 2016). Catastrophic life events, social disequilibrium, business failure, personal dilemmas, and unhappiness can encourage individuals to engage in nontypical activities. Evidence suggests that incidences of suicide may increase as people are unable to handle socio-economic and environmental pressure. The maintenance of social distancing and absence of daily routines may also encourage the risk of suicidal behavior (Streva, 2020). Accordingly, the crisis has increased the number of cases of suicide across the globe.

The lockdowns imposed across the globe have accelerated domestic violence against women and children, as well as criminal activity and the illegal cultivation of cannabis and other drugs. The United Nations Secretary General, Antonio Guterres, has stated that the "horrifying global surge in domestic violence" directed towards women and girls is linked to lockdowns imposed by governments responding to the COVID-19 pandemic. ${ }^{5}$ The Brazilian judge Mello Adriana said that "we think there has been a rise of $40 \%$ to $50 \%$, and there was already really big demand [for legal services]; we need to stay calm in order to tackle this difficulty we are now facing." Further, in Wuhan city in China, a retired police officer reported that more than 90 percent of familyviolence-related incidents during the lockdown were closely associated with the outbreak of coronavirus (Harrison et al, 2020). Amanda Taub claims that government-imposed restrictions on the movement of people that have forced people to stay at home throughout the world in response to the virus have

5 Decries 'horrifying' rise in domestic violence amid virus lockdown. https://www.france24.com/ en/20200406-un-chief-decries-horrifying-rise-in-domestic-violence-amid-virus-lockdown. Accessed on 18 April 2020. 
resulted in an increase in intra-family violence (Amanda. 2020). The lockdown has had profound implications for the structure, function, and stability of family management. Nicole et al. revealed that the outbreak of COVID-19 lockdown means a challenging time for the victims of family members (Westmarland. et al, 2020). The pandemic has disturbed both the social and biological relationships of families, and resulted in violence, abuse, and threats between both husbands and wives, and children and other members of families. It has adversely affected the emotional, moral, mental, social, and behavioral patterns of families, and is subsequently causing the maladjustment of children, impaired relationships, financial misery, and stress. Women-centered policing units in lockdown countries have received numerous complaints about family violence. Fried Ina states that the crisis of family violence has drastically increased due to mass psychological depression, stress, and anxiety, as well as the need to stay at home and financial distress caused by the COVID-19 lockdown (Fried, 2020). Exposure to large-scale family distress, financial difficulties, job losses, income sources and sociocultural determinants, as well as social isolation and psychological pressure has increased the likelihood of domestic violence. In addition to this, a rise in crime and the illegal cultivation of drugs have also been reported in many places in the world. Crimes like stealing and burglary involving money, gold jewelry, and domestic household items have been reported in many places in India where family members are lodged in quarantine centers (Haq, 2020). The illegal cultivation and production of cannabis and other illicit drugs has also been on the rise. Fertig and his associates have stated that "cannabis products will find its moment amid the coronavirus outbreak" (Natalie et al, 2020). It is believed that an outbreak of coronavirus will increase the legalization of the cultivation and production of cannabis legalization products in the United States (Mann, 2020). Experts believe that the coronavirus outbreak will increase the production and consumption of illicit harmful drugs, which may pose a great threat to the physical and mental health of individuals. In general, the epidemic of coronavirus disease is not only merely a global health problem, but a social problem as well due to the fear and threat of stigma, discriminatory behavior, social isolation, forced quarantine, violation of human rights, violence, suicidal ideation, and social phobia.

\section{PSYCHOLOGICAL IMPLICATIONS OF COVID-19}

The outbreak of the COVID-19 crisis has had disastrous implications for the growth and development of the psychological and mental health of people. 
Dr. Hans Henri P. Kluge, Regional Director of WHO Europe, in a statement entitled "Mental health and psychological resilience during the COVID-19 pandemic," reported that the pandemic crisis has caused a lot of worries, threat, fear, anxiety, stress and panic among the people affected by it, which has resulted in significant mental health deterioration and mass psychological pressure (Kluge, 2020). A study carried out by Cuiyan Wang in 24 cities in China with a sample of 1210 respondents found that $53 \%$ of respondents had experienced psychological pressure, of whom $16.5 \%$ indicated depressive disorders, $28.8 \%$ anxiety disorder, and $8.1 \%$ stress (Cuiyan et al, 2020). It has also come to the forefront that patients with hypertension, cardiac disease, diabetes mellitus, and cerebrovascular disease are at greater risk of coronavirus infection and psychological distress (Fang et al, 2020 - Eastin, C., \& Eastin, T. (2020)). A study entitled "Outbreak of COVID-19 and its impact on global mental health" conducted by Julio Torales stated that the coronavirus crisis epidemic will increase, on a global basis, mental health challenges such as depression, frustration, anxiety, stress, insomnia, dread, rage, negation, and pressure (Torales et al, 2020). The epidemic has provoked great fear, depression, and stress among the masses worldwide and led them into a state of chaos and confusion. Health professionals such as doctors, nurses, and other paramedic staff are more vulnerable to the risk of mental health and psychiatric problems, especially when they handle coronavirus patients (Neil et al, 2020). Xiang et al. observed that recovered coronavirus patients suffer from self-doubt, feelings of aloneness, fury, boredom, frustration, uneasiness, depression, sleepless disorder, and post-traumatic stress due to false social media portrayals, physical malaise, incertitude, and lack of contact and alienation (Xiang et al, 2020). Teens and children who are under home quarantine and in quarantine centers may be seriously psychologically afflicted, and those whose loved ones have died or were affected by coronavirus may suffer from long-lasting effects in terms of mental health and psychological well-being (Jia et al, 2020). Sprang and his associates have claimed that kids and teenagers who are separated and locked down in quarantined locations such homes, health centers, and other places during the pandemic may be prone to stress, sadness, distress, and behavioral- and depression-related disorders (Sprang et al, 2020). The crisis has created great panic that affects psychological health, and has harmed individuals in many ways: it has created panic, stress disorders, phobia, depression, anxiety disorders, and insomnia. It has created anxiety to such an extent that it has increased the risk of psychiatric disorders, trauma and mental health problems like mood disorders, behavioral disorders, depressive disorders, headaches, sleep terrors, hypertension, frustration, aggression, nervousness, suicide ideation, fear, flashbacks, and strain, making individuals feel insecure, fragile, 
and volatile. Yenan Wang found that psychological problems like anxiety and depression are more typical among females, older people, and those with a masters' degree compared to males, young people, and those with vocational degrees (Wang et al, 2020). Importantly, it has caused stress, fear, and worry among vulnerable groups, as well as children and teens, women, pregnant women, those with chronic disease, medical professionals, healthcare experts, security personnel, psychiatric patients, and people who suffer from substance use disorder. ${ }^{6}$

The devastating consequences of the pandemic crisis, particularly when combined with the impacts of economic recession and the socio-cultural environment, have increased chaos, confusion, and disruption among individuals, sparking widespread psychological distress. The study "The psychological impact of quarantine and how to reduce it: rapid review of the evidence" conducted by a team of experts observed that quarantine and social isolation have caused unprecedented mental health problems such as post-traumatic stress symptoms, upset and anger, stress-related factors such as frustration, fear (of infection), loneliness, fatigue, dissatisfaction, as well as aggression, strain, suicidal thoughts, anxiety-related disorders, social phobia, disillusionment, and unhappiness (Brooks et al, 2020). Many psychologists have reported that social isolation, separation from family, sudden deaths, epidemics, divorce, alienation, and the death of parents and loved ones during early childhood can have longlasting effects on mental health, and lead to the development of psychological disorders such as moodiness, stress, anxiety, and suicidal thoughts later in life (Torsten et al, 2015). In addition, pressure and distress can cause health worries, changes in sleeping pattern, escalating health problems, alterations in eating patterns, and may increase the susceptibility of vulnerable individuals to engaging in unbeneficial activities. ${ }^{7}$ Yeen Huang found that medical professionals and young people who spend more time on their day-to-day routines are prone to psychological distress. Moreover, the study found that $35.1 \%$ of individuals reported having anxiety symptoms, $20.1 \%$ depressive symptoms, and $18.2 \%$ poor sleep quality. Among these, young medical professionals reported an increase in the prevalence of anxiety symptoms and sleep disorders (Huang et al, 2020). Keeping social distance and self-isolating from one's family, social groups, and community during quarantine may lead to anxiety, boredom, loneliness, and depressive disorders, and significantly affect mental health. Verena H Menec and his colleagues found that being socially isolated, a lack of companionship, and feelings of loneliness are connected with the provision of social services and gaps

6 www.cdc.gov/center.com

7 www.Samhsa.gov.in

CORVINUS JOURNAL OF SOCIOLOGY AND SOCIAL POLICY VOL. 11 (2020) 2 
thereof; affected individuals are also at heightened risk of mass psychological disturbances (Menec et al, 2020). A research article published in the Lancet reported an increase in the incidence of symptoms such as confusion, anger, fear, anxiety disorder, depressive disorder, and post-traumatic stress disorder among people living in home-quarantine and quarantine centers, which could have long-term effects on their psychological health (James, 2020). Needless to say, the exposure to a diverse range of factors associated with the pandemic crisis has increased the risk of psychological problems and mental health deterioration among large segments of population, particularly those directly affected by the virus such as health workers and families.

\section{DISCUSSION}

This study has examined the socio-psychological implication of the dynamic outbreak of COVID-19 across the world. Based on the findings of various research articles, journals, experts, media reports, and those of international organizations about the psychological implications of the outbreak of coronavirus, it appears that the COVID-19 pandemic has significantly affected the mental health of people generally and in different ways, such as economic recession, loss of jobs, financial stress, forced quarantine, direct infection with the virus, loss of loved ones due to the virus, social distancing, lack of community support, abstinence from engagement with religious activities, social isolation, feelings of loneliness, social stigma, discrimination, and the lack of day-to-day routine activities. All these negative aspects significantly impact the mental health of individuals. The coronavirus crisis has therefore created multidimensional problems around the globe, and in every area of life, whether health, social-psychological, political, economic or educational, and has increased the chance of a solitary life, alienation, loneliness, ostracism, exclusion, chaos, and a state of confusion among individuals.

The outbreak of COVID-19 has become a major public health issue and thus needs a worldwide response. This plague has brought together international agencies and communities worldwide on one platform to suggest possible solutions. COVID-19 has created new challenges for medical professionals, different international organizations and communities, who are striving to respond and plan for this global situation of turmoil. The political, social, economic, technological, environmental, cultural, and educational issues have been brought to the forefront by the outbreak of COVID-19 (The Lancet, editorial, 2020). It is clear that the epidemic of coronavirus has had grave consequences 
for every sector of society, including family, economy, policymaking, religion, and education, as well as physical and mental health. Combating this pandemic requires serious and immediate attention from all stakeholders, policymakers, and health professionals, thus governments across the globe have a vital role to play. There is an urgent need for the formulation of policies and programs that help reduce and control the plague, and help the most affected sectors of society. Prospective suggestions pertaining to COVID-19 are manifold. First, greater attention should be paid to those vulnerable individuals in society such as daily wage laborers, senior citizens, and the healthcare staff who are battling with this epidemic. Second, adequate psychological counseling and guidance should be given to those people who are infected with coronavirus; who are quarantined in homes and other places; and more importantly, to children, elderly people, and doctors and nurses. Third is psychological help for affected individuals and their families in the form of individual counseling, group therapy, family counseling, group counseling, psychological education, and psychological interventions. Counseling and mental-health assessment clinics should be established to reduce the psychological disorders experienced by people due to coronavirus. Adequate financial and other relief should be given to needy sectors of society. The government should relax its terms for loan holders, farmers, and money lenders. The government should also help those families who have lost their main breadwinner. The healthcare system, training programs and skills, and other medical facilities should be strengthened to ameliorate the present health crisis. The authorities and health professionals that are involved in battling COVID-19, such as doctors, nurses, and other paramedic staff, should pay great attention and care to the physical and mental health status of people, badly affected by the outbreak of the coronavirus disease.

\section{CONCLUSION}

The outbreak of the COVID-19 crisis has severely affected many sections of society throughout the world. The epidemic of COVID-19 has raised numerous challenges for families, communities, law enforcement agencies, policymakers, international organizations, planning initiatives and programmes, as well as health-related services on a global level. Criminality, mass psychological trauma, mental health distress, financial distress, reverse migration, the disruption of social networks and essential services, the growing incidence of domestic violence, poverty and unemployment, stigma, social isolation and deprivation are some of the grave implications that go beyond the direct health crisis associated with 
the outbreak of COVID-19. The COVID-19 pandemic has caused tremendous pressure, frustration, and stress among people across the globe, putting them into a state of confusion and chaos. In all developing countries, it is having grave repercussions for all strata of society, and resulting in severe individual, family, socio-economic and mental health problems. Governments, civil society, and stakeholders need to reach out to the poor and the needy in society to curb the spread of the COVID-19 disease. While no potential vaccine has yet been administered to cope with COVID-19, it is incumbent to cooperate with administrative and law-enforcement agencies. More importantly, the outbreak has provided an opportunity for every nation to strengthen its health-care, build better, safer, and more welcoming hospitals, and to provide enhanced medical services. In fact, the novel coronavirus has revealed a lack of skills and coordination, technology, policies and planning, training, and preparedness, while other areas also need to be addressed immediately in order to fight it. Furthermore, it is essential to intensify public awareness and implement prevention programs in society.

\section{REFERENCES}

Amanda, T (2020) A New Covid-19 crisis: Domestic Abuse Rises Worldwide. New York Times, Retrieved from, https://www.nytimes.com/2020/04/06/ world/coronavirus-domestic-violence.htmll/, Accessed on 7 April, 2020

Armitage, R -Nellums, L. (2020) The COVID-19 response must be disability inclusive. The Lancet Public Health, Vol. 5, No. 5, pp. 257. https://doi. org/10.1016/s2468-2667(20)30076-1

Bo, H -Li, W -Yang, Y -Wang, Y Zhang, Q -Cheung, T. (2020) Posttraumatic stress symptoms and attitude toward crisis mental health services among clinically stable patients with COVID-19 in China. Psychological Medicine, pp. 1-2. https://doi.org/10.1017/s0033291720000999

Brooks, S K - Webster, R -Smith, L - Woodland, L -Wessely, S -Greenberg, N -Rubin, G. (2020) The psychological impact of quarantine and how to reduce it: rapid review of the evidence. The Lancet, Vol. 395, No. 10227, pp. 912-920. https://doi.org/10.1016/s0140-6736(20)30460-8

Carvalho, P - Moreira, M -de Oliveira, M. -Landim, J -Neto, M. (2020) The psychiatric impact of the novel coronavirus outbreak. Psychiatry Research, Vol. 286, pp.112902. https://doi.org/10.1016/j.psychres.2020.112902

Chen, T -Wu, D -Chen, H -Yan, W -Yang, D -Chen (2020) Clinical characteristics of 113 deceased patients with coronavirus disease 2019: retrospective study. British Medical Journal, pp. m1091. https://doi.org/10.1136/bmj.m1091 
Cerami, C -Santi, G -Galandra, C -Dodich, A -Cappa, S -Vecchi, T -Crespi, C. (2020) COVID-19 Outbreak in Italy: Are We Ready for the Psychosocial and Economic Crisis? Baseline Findings from the Longitudinal PsyCovid Study. SSRN Electronic Journal., Vol. 11 https://doi.org/10.2139/ ssrn.3569868

Daniels, J. (2020) Venezuelan migrants "struggling to survive" amid COVID-19. The Lancet, Vol. 395, No. 10229, pp. 1023. https://doi.org/10.1016/ s0140-6736(20)30718-2

Dutheil, F -Aubert, C -Pereira, B -Dambrun, M -Moustafa, F -Mermillod, M. et al. (2019) Suicide among physicians and health-care workers: A Systematic review and meta-analysis. PLOS ONE, Vol. 14, No.12, pp. e0226361. https:// doi.org/10.1371/journal.pone.0226361

Eastin, C -Eastin, T. (2020) Clinical Characteristics of Coronavirus Disease 2019 in China. The Journal Of Emergency Medicine, Vol .58 No.4, pp. 711-72. https://doi.org/10.1016/j.jemermed.2020.04.004

Fang, L - Karakiulakis, G -Roth, M. (2020) Are patients with hypertension and diabetes mellitus at increased risk for COVID-19 infection? The Lancet Respiratory Medicine, Vol. 8, No. 4, pp. e21. https://doi.org/10.1016/s22132600(20)30116-8

Fried, I (2020) Increase in domestic violence feared in coronavirus lockdown. Axios Retrieved from , https://www.axios.com/coronavirus-domesticviolence-de98b402-51f2-49ec-919c-c70052e29eef.html, Accessed on 4 April, 2020.

Greenberg, N -Docherty, M -Gnanapragasam, S -Wessely, S. (2020) Managing mental health challenges faced by healthcare workers during covid-19 pandemic. British Medical Journal, pp. m1211. https://doi.org/10.1136/bmj. $\mathrm{m} 1211$

Haq, S (2020), Thieves steal Rs 3 lakh from house of Kashmiri family quarantined after covid-19 detection. India Today, Reterieved from https:// www.indiatoday.in/india/story/thieves-steal-rs-3-lakh-from-house-fromkashmiri-family-quarantined-after-covid-19-detection-1661342-2020-03-30, Accessed on 2 April, 2020.

Harrison, M -Giuffrida, A (2020), Lockdowns around the world bring rise in domestic violence. The Guardian, Reterieved from, https://www.theguardian. $\mathrm{com} /$ society $/ 2020 / \mathrm{mar} / 28 /$ lockdowns-world-rise-domestic-violence, Accessed on March 29, 2020.

James, N (2020), How coronavirus affects your mental health and ways to cope. The Hindu, Retrieved from, https:/www.thehindubusinessline.com/news/ variety/how-coronavirus-affects-your-mental-health-and-ways-to-cope-/ article31170544.ece. Accessed on 27 March 2020 
Jeff, L (2020), In the coronavirus age, loneliness and social isolation are pressing concerns for healthcare. HealthCare Finance, Retrieved from: https://www. healthcarefinancenews.com/news/coronavirus-age-loneliness-and-socialisolation-are-pressing-concerns-healthcare. Accessed on 24 April 2020

Kim,H (2020) How countries across the globe respond COVID-19. U.S.A Today. Retrieved From https://www.ustoday.com/story/news/world/2020/03/17/ coronavirus-how-countries-across-globe-responding-covid-19/5065867002. Last accessed on 27/04/2020.

Kluge, H -Henri, P. (2020) Mental Health and Psychological Resilience during the COVID-19 Pandemic. World Health Organization Europe, Retrieved from http://www.euro.who.int/en/health-topics/health-emergencies/coronaviruscovid-19/news/news/2020/3/mental-health-and-psychological-resilienceduring-the-covid-19-pandemic. Accessed on April 21, 2020

The Lancet Infectious Diseases (2020) Challenges of coronavirus disease 2019.

The Lancet Infectious Diseases, Vol. 20, No. 3, pp. 261. https://doi.org/10.1016/ s1473-3099(20)30072-4

Lacobucci, G. (2020) Covid-19: Doctors warn of humanitarian catastrophe at Europe's largest refugee camp. BMJ, pp. m1097. https://doi.org/10.1136/bmj. m1097

Lacobucci, G (2020) Covid-19: Lack of PPE in care homes is risking spread of virus, leaders warn. $B M J$, pp. m1280. https://doi.org/10.1136/bmj.m1280

Mahase, E. (2020) Covid-19: WHO declares pandemic because of "alarming levels" of spread, severity, and inaction. BMJ, pp. m1036. https://doi. org/10.1136/bmj.m1036

Mann, E.W (2020), Coronavirus could accelerate US cannabis legalization. Yahoo Finance, Retrieved from, https://in.finance.yahoo.com/amphtml/news/ coronavirus-could-accelerate-us-cannabis-legalization-153011559.html., Accessed on 22 March 2020

Moukaddam Nidal and Shah Asim (2020) Psychiatric Beware. The impact of covid-19 and pandemic on mental health. Psychiatric Times, Vol. 37, Issue 3, pp. 1-16.

Mayor, S. (2020) Covid-19: Researchers launch app to track spread of symptoms in the UK. $B M J$, pp. m1263. https://doi.org/10.1136/bmj.m1263

Menec, V -Newall, N -Mackenzie, C -Shooshtari, S -Nowicki, S. (2020) Examining social isolation and loneliness in combination in relation to social support and psychological distress using Canadian Longitudinal Study of Aging (CLSA) data. PLOS ONE, Vol. 15, No. 3, pp. e0230673 https://doi. org/10.1371/journal.pone.0230673

Mukherjee Rabindra N \& Ghosal Arunansu (2006). Social thought from Comte to Mukerjee, published by Vivek Prakshan, New Delhi. 
Natalie,F -Mona ,Z -Paul,D (2020) Cannabis finds its moment amid coronavirus outbreak. Retrieved from, https://www.politico.com/news/2020/03/27/ cannabis-coronavirus-151209, Accessed on 29 March, 2020.

Oyesanya, M -Lopez-Morinigo, J -Dutta, R. (2015) Systematic review of suicide in economic recession, World Journal Of Psychiatry, Vol. 5, No. 2, pp. 243. https://doi.org/10.5498/wjp.v5.i2.243

Peter (2020) Hundreds dead in Iran after consuming methanol thinking it was coronavirus protection. Retrieved From https:// www.foxnews.com/world/ hundrends-dead-iran-methanol-coronavirus-protection., Accessed on 27 March 2020

Qiu, J- -Shen, B -Zhao, M -Wang, Z -Xie, B -Xu, Y. (2020) A nationwide survey of psychological distress among Chinese people in the COVID-19 epidemic: implications and policy recommendations. General Psychiatry, Vol. 33, No. 2, pp. e100213. https://doi.org/10.1136/gpsych-2020-100213

Reger, M -Stanley, I -Joiner, T. (2020) Suicide Mortality and Coronavirus Disease 2019-A Perfect Storm? JAMA Psychiatry. Vol. 11, No. 77, pp. 1093. https://doi.org/10.1001/jamapsychiatry.2020.1060

Santavirta, T-Santavirta, N -Betancourt, T -Gilman, S. (2015) Long term mental health outcomes of Finnish children evacuated to Swedish families during the second world war and their non-evacuated siblings: cohort study. BMJ, Vol. 350, No. 1, pp. g7753-g7753. https://doi.org/10.1136/bmj.g7753

Singh Ramesh (2020). Age-structured impact of social distancing on the COVID-19 epidemic in India, ArXiv: 2003.12055v1 [q-bio.PE].

Sprang, G -Silman, M. (2013) Posttraumatic Stress Disorder in Parents and Youth after Health-Related Disasters. Disaster Medicine And Public Health Preparedness, Vol. 7, No. 1, pp. 105-110. https://doi.org/10.1017/ dmp.2013.22

Torales, J -O'Higgins, M -Castaldelli-Maia, J -Ventriglio, A. (2020) The outbreak of COVID-19 coronavirus and its impact on global mental health. International Journal Of Social Psychiatry, Vol. 66, No. 4, pp. 317320. https://doi.org/10.1177/0020764020915212

UNICEF (2020) Social stigma associated with the coronavirus disease (COVID-19). Retrieved from Www.unicef.org, Accessed on 22 April 2020.

VanderWeele, T -Li, S -Tsai, A -Kawachi, I. (2016) Association between Religious Service Attendance and Lower Suicide Rates among US Women. JAMA Psychiatry, Vol. 73, No. 8, pp. 845. https://doi.org/10.1001/ jamapsychiatry.2016.1243

Virginia,S (2020), Social distancing efforts could spur suicide as COVID-19 crisis plays out. Retrieved from, https://www.phillyvoice.com/social- 
distancing-suicide-isolation-coronavirus-covid-19-telehealth-depressionunemployment., Accessed on 24 April 2020.

Wang, C -Pan, R - Wan, X - Tan, Y -Xu, L -Ho, C -Ho, R. (2020) Immediate Psychological Responses and Associated Factors during the Initial Stage of the 2019 Coronavirus Disease (COVID-19) Epidemic among the General Population in China. International Journal Of Environmental Research And Public Health, Vol. 17, No. 5, pp. 1729. https://doi.org/10.3390/ijerph17051729 Wang, Y -Di, Y -Ye, J -Wei, W. (2020) Study on the public psychological states and its related factors during the outbreak of coronavirus disease 2019 (COVID-19) in some regions of China. Psychology, Health \& Medicine, Vol. 26, No. 1, pp, 13-22 https://doi.org/10.1080/13548506.2020.1746817

Westmarland,N -Bellini, R .(2020), Coronavirus lockdown is a dangerous time for victims of domestic abuse-here's what you need to know. The Conversation, Retrieved from, https://www.theconversation.com/coronavirus-lockdown is-a-dangerous-time-for-victims-of-domestic-abuse-heres-what-you-need-toknow-134072. Accessed on 25 March 2020

WHO (2013), Mental Health Action Plan 2013-20., World Health Organisation, Geneva:. . Retrieved at https://apps.who.int/iris/rest/bitstreams/424776/ retrieve

World Bank. (2020) People, pathogens and our planet: The economics of one health. Retrieved from: http://documents.worldbank.org/curated/ en/612341468147856529/Peoplepathogens-and-our-planet-the-economics-ofone-health. Accessed on February 29, 2020

Xiang, Y -Yang, Y -Li, W -Zhang, L -Zhang, Q -Cheung, T -Ng, C. (2020) Timely mental health care for the 2019 novel coronavirus outbreak is urgently needed. The Lancet Psychiatry, Vol. 7, No. 3, pp. 228-229. https://doi. org/10.1016/s2215-0366(20)30046-8)

Yeen,H -Ning, Z (2020) Huang Yeen et al (2020). Mental health burden for the public affected by the COVID-19 outbreak in China: Who will be the high-risk group? Psychology, Health \& Medicine, Vol. 26, No. 1, pp. 23-34, DOI: 10.1080/13548506.2020.1754438

Zhou, F -Yu, T -Du, R -Fan, G -Liu, Y -Liu, Z. et al. (2020) Clinical course and risk factors for mortality of adult inpatients with COVID-19 in Wuhan, China: a retrospective cohort study. The Lancet, Vol. 395, No. 10229, pp. 1054-1062. https://doi.org/10.1016/s0140-6736(20)30566-3) 
